\title{
Revisión sistemática de investigaciones sobre videojuegos bélicos (2010-2020)
}

M. Esther del Moral Pérez

Universidad de Oviedo (España)

Christian Rodríguez González

Universidad de Oviedo (España) 



\title{
Revisión sistemática de investigaciones sobre videojuegos bélicos (2010-2020)
}

\section{Systematic review of investigations on war video games (2010-2020)}

\author{
M. Esther del Moral Pérez \\ Universidad de Oviedo (España) \\ emoral@uniovi.es \\ Christian Rodríguez González \\ Universidad de Oviedo (España) \\ chris.rg87@gmail.com
}

Fecha de recepción: 23 de mayo de 2020

Fecha de aceptación: 18 de noviembre de 2020

\section{Resumen}

Se analiza la producción científica sobre videojuegos bélicos. La metodología se sustenta en una revisión sistemática de estudios extraídos de bases de datos (Scopus, Web Of Science y Google Scholar), mediante un meta-análisis, siguiendo criterios de PRISMA-P2015 para identificar los enfoques y metodologías empleadas. Se encontraron 37 estudios entre 2010-2020 en cuatro ámbitos: educativo, psicológico, sociológico o antropológico y tecnológico. Los resultados ofrecen un panorama polarizado, un sector los considera plataformas de propaganda militarista; otro apuesta por utilizarlos como un recurso didáctico, permitiendo la inmersión virtual en acontecimientos históricos; y los técnicos señalan la conveniencia de diseñar videojuegos educativos con el asesoramiento de historiadores para dotarlos de mayor fiabilidad, además de incorporar misiones gamificadas que potencien su jugabilidad. Sin embargo, se precisan estudios que profundicen en la oportunidad que ofrecen estos instrumentos para impulsar el pensamiento crítico y la reflexión frente a la guerra y el sufrimiento de las víctimas.

Palabras clave: Videojuegos bélicos; Educación; Pensamiento crítico; Diseño; Militarización 
Revisión sistemática de investigaciones...- M.E. del Moral y C. Rodríguez

\begin{abstract}
Scientific production on war videogames is analyzed. The methodology is based on a systematic review of studies extracted from databases (Scopus, Web of Science and Google Scholar), through a meta-analysis, following the criteria of PRISMA-P2015 to identify the approaches and methodologies used. Thirty-seven studies were found between 2010-2020 in four areas: educational, psychological, sociological or anthropological and technological. The results offer a polarized panorama, one sector considers them militarist propaganda platforms; another is committed to using them as a didactic resource, allowing virtual immersion in historical events; and the technicians point out the convenience of designing educational video games with the advice of historians to make them more reliable, in addition to incorporating gamified missions that enhance their playability. However, studies are needed to delve into the opportunity offered by these instruments to promote critical thinking and reflection in the face of war and the suffering of the victims.
\end{abstract} rization

Key words: War videogames; Education; Critical thinking; Design; Milita-

\title{
1. INTRODUCGIÓN
}

La irrupción de los videojuegos bélicos en el panorama del entretenimiento digital provocó una gran conmoción, para algunos ha resultado ser el negocio más beneficioso del siglo por el volumen de mercado que genera (Forde, 2020). Simultáneamente, se levantaron voces que cuestionaban la legitimidad de estos instrumentos lúdicos, por banalizar la guerra y convertirse en una sofisticada fórmula de alienación colectiva sin referentes éticos (Dyer-Witheford \& De Peuter, 2009), o por sumergir al jugador en la acción, convirtiéndolo en una máquina de exterminar enemigos sin reflexionar sobre los motivos (Navarro, 2017). Algo más tarde, apareció una tercera vía -desde una perspectiva didáctica-, que ha intentado aprovechar estos escenarios lúdicos para conocer la guerra, utilizando su capacidad inmersiva y realismo para aprender historia, y conocerla a través de sus narrativas e interacciones con gran libertad rompiendo con la linealidad de los relatos cinematográficos (Frasca, 2009).

La preocupación por ganar adeptos a estos juegos ha generado estudios desde un enfoque técnico para mejorar sus mecánicas, dinámicas y estéticas, para ofrecer a los usuarios una experiencia de juego más gratificante, garantizando la jugabilidad y dotándolo de un componente social (Walk, Görlich \& Barrett, 2017). Otros se centran en analizar cómo se favorece la inmersión del jugador mediante historias con una mayor profundidad y carga narrativa (Christy \& Fox, 2016). De forma semejante, surgen investigaciones preocupadas por analizar la fidelización de los jugadores y sus motivaciones para permanecer vinculados a los videojuegos (Del Moral \& Guzmán, 2017). Sin duda, el atractivo de los gráficos, la capacidad envolvente de la historia, el realismo de los escenarios, la personalización de los avatares, la posibilidad de juego cooperativo, etc., son elementos intrínsecos a los juegos que están generando 
nuevas líneas de desarrollo ligadas al diseño de entornos inmersivos, implementando tecnologías emergentes como la realidad aumentada o virtual (Carvalho et al., 2016).

Así pues, se constata que los estudios sobre videojuegos bélicos han ocupado un gran espacio en diversos ámbitos del conocimiento, suscitando diferentes investigaciones que subrayan el interés por estos controvertidos artefactos lúdicos que aglutinan a grandes colectivos. Algunos critican la trivialización que hacen de la guerra, la excesiva violencia gratuita que presentan (Pötzsch, 2017), la militarización de la sociedad (Clearwater, 2010), las conductas adictivas que generan (Bean et al., 2017), etc. Otros ponen énfasis en las aportaciones al campo educativo, por las oportunidades que ofrecen para potenciar determinadas habilidades como el juego en equipo, el aprendizaje de estrategias para resolver problemas (Carvajal, Rojas \& Murcia, 2016; West, Crooks \& Bradley-Ho, 2018), el análisis de conflictos históricos (García-González, 2016); la aproximación a hechos y personajes históricos (Rockwood \& Palmer, 2011), etc.

En este sentido, la presente revisión sistemática pretende identificar los distintos enfoques y metodologías adoptadas por las diferentes investigaciones -de la última década- centradas en estos instrumentos de ocio, para ver las tendencias y elementos que priorizan. De forma especial, se focaliza al análisis de aquellas que se relacionan con el ámbito de la educación, para constatar las diversas aproximaciones al fenómeno. Diferenciando, por un lado, las investigaciones y experiencias que los conciben como instrumentos didácticos integrados en el aula, y por otro, aquellas que utilizan videojuegos diseñados con una intencionalidad educativa -o serious games- desde planteamientos reflexivos y críticos.

\section{DIFERENTES PERSPECTIVAS EN LA INVESTIGACIÓN SOBRE VIDEOJUEGOS}

Las investigaciones acerca de videojuegos bélicos han sido abordadas desde diversos ámbitos, tales como el educativo, el psicológico, el sociológico y técnico.

\section{1. Ámbito educativo}

Los estudios ligados al ámbito educativo se dividen, por un lado, en aplicaciones didácticas y en análisis de su contribución para potenciar el pensamiento crítico. Así, los primeros analizan su implementación en aulas de secundaria para ver cómo activan el aprendizaje de contenidos históricos determinados juegos como Age of Empires y Empire Earth o Medal of Honor: European Assault y Making History (Cuenca \& Martín, 2010; Fisher, 2011; Watson, Mong \& Harris, 2011) y habilidades cognitivas (Unsworth et al., 2015). Algunos constatan cómo juegos relacionados con la I y II Guerra Mundial -Valiant Hearts, Darkest Hour, Commandos: The Great War, Verdun y Making History- ayudan a contrastar hechos históricos (Gish, 2010; Holdijck, 2016; 
O’Neill \& Feenstra, 2016). Otros estudian el desarrollo de competencias de índole histórica (Carvalho, 2017), impulsan el aprendizaje emocional (Marcano, 2014), y la motivación del alumnado para aprender historia con juegos como Total War: Roma II (Camarero, 2019). También posibilitan el estudio de las variables científico-tecnológicas implicadas en la guerra utilizando estos juegos (García-González, 2016).

Otras investigaciones ligadas al ámbito educativo se centran en estudiar cómo pueden algunos videojuegos bélicos fomentar el pensamiento crítico y la empatía histórica (Boltz, 2017). Concretamente, Alhabash y Wise (2015) utilizan el serious game Peacemaker para provocar cambios de actitud en los jugadores respecto al conflicto árabe-israelí. Por su parte, Burguess et al. (2011) analizan cómo la representación estereotipada de personajes de color en los videojuegos bélicos, provoca en los jugadores una vinculación de éstos con la violencia, además constatan la poca representación femenina. Chapman (2016), Metzger y Paxton (2016) y Šsler (2016) alertan de que algunos videojuegos como el Czechoslovakia 38-89: Assassination omiten detalles importantes relativos a la memoria histórica de la I GM, lo que puede llevar a una simplificación de lo acontecido realmente.

\section{2. Ámbito psicológico}

Los estudios ligados a la psicología se orientan, por un lado, a la validación psicométrica de instrumentos de medida de distintos constructos, tales como la capacidad inmersiva que poseen los videojuegos para concentrar la atención de los sujetos e involucrarles en las tareas o misiones que proponen (Cheng, She \& Annetta, 2014). $\mathrm{O}$, el compromiso o grado de fidelización de los jugadores con determinados videojuegos (Zaib, Hool \& Hlavacs, 2016).

Por otro, están los estudios dirigidos al análisis de los efectos de los videojuegos en los jugadores. En algún caso, observando la posible adicción generada por los MMORPG (Maganuco et al., 2019). En otro, analizando la relación entre la capacidad inmersiva de un videojuego y la experiencia de juego que proporciona (Örtqvist \& Liljedahl, 2010). O, más concretamente, constatando la desconexión moral provocada en adolescentes tras someterlos a videojuegos violentos (Teng et al., 2019). Asimismo, el estudio de Weibel y Wissmath (2011) constata cómo las variables presencia de los jugadores -en los mundos creados por distintos videojuegos (Neverwinter $\mathrm{Ni}$ ghts, Formula 1 y Sonic The Hedgehog)-, y el flujo o implicación del jugador en las misiones propuestas, influyen tanto en la superación de los retos, la promoción de nivel dentro del juego, como en el disfrute que de ello se deriva.

\section{3. Ámbito sociológico y antropológico}

Estas investigaciones abordan problemáticas ligadas a los videojuegos bélicos desde un enfoque socio-crítico, socio-político y/o ético. Así, Nardone (2017) analiza 
cómo estos videojuegos contribuyen a modificar la percepción de la guerra en los jugadores, al primar lo lúdico por encima de lo realista, minimizando la repercusión de la violencia en las víctimas. Por su parte, García-Moreno (2017) evidencia cómo en determinados videojuegos como la saga Metal Gear se representa con gran precisión el contexto histórico-político de la Guerra Fría. Por contra, Donald (2019) observa el realismo del armamento utilizado y los emplazamientos ofrecidos por algunos videojuegos, sin embargo se difuminan los elementos dramáticos de la guerra. De forma semejante, González e Igartua (2020) concluyen que este tipo de videojuegos obvian las causas reales de los conflictos bélicos, concentrando la atención del jugador en la lucha por defenderse de los embates enemigos, invisibilizando a los civiles, lo que le resta realismo. Igualmente, Verino (2019) al examinar la saga Call of Duty en relación con la II GM, constata una visión sesgada de la guerra, exenta de la participación de civiles y de la representación de su sufrimiento.

Otros estudios denuncian que la mayoría de estos videojuegos son un medio propagandístico de la militarización, al mostrar una visión reduccionista y sesgada de la guerra. Concretamente, Saber y Webber (2017) abordan la plasmación de la ideología del ISIS en videojuegos como Special Force 1 y 2 para justificar las acciones del yihadismo. De modo similar, Robinson (2012), Robinson y Schulzke (2016), y Shaw (2010) analizan cómo determinados videojuegos están impregnados de la ideología pro-bélica norteamericana. Por su parte, Payne (2014) compara los discursos narrativos de varios videojuegos, afirmando que en Spec Ops: The line se muestra un enfoque de la guerra más crítico y reflexivo sobre sus consecuencias, que los de la saga Call of Duty donde se prima lo lúdico centrado en ejecuciones irreflexivas.

\section{4. Ámbito tecnológico}

Los estudios procedentes del ámbito tecnológico se preocupan por analizar asá pectos ligados al diseño técnico de los videojuegos, tales como las mecánicas y dinámicas. En este sentido, De Lope et al. (2017) establecen las pautas que deben primarse en el diseño de un serious game, combinando la jugabilidad con los objetivos educativos para no caer en el excesivo didactismo. Desde otra perspectiva, Hanes y Stone (2019) critican la falta de rigurosidad histórica de algunos videojuegos comerciales y proponen una metodología para presentar los contenidos instruccionales históricos de forma rigurosa. Más concretamente, De Smale, Kors y Sandovar (2019) analizan el proceso de diseño y documentación realizado por los diseñadores del videojuego This War of Mine, apoyado en entrevistas a supervivientes y víctimas de guerra, para dotar de verosimilitud a la historia y suscitar dilemas morales que ayuden al jugador a reflexionar.

Por su parte, Díaz (2014) examina el serious game Contra Viento y Marea para conocer el funcionamiento del mismo y sus elementos gamificables para lograr sensibilizar al alumnado frente a la problemática de los refugiados, y cambiar su actitud 
mediante las respuestas que tienen que dar a los dilemas representados. Por último, convencidos de la utilidad de los videojuegos o aplicaciones lúdicas ligadas al aprendizaje, Maniega, Yanez y Lara (2011) formulan las fases para diseñar un serious game, a partir de la descripción de un prototipo, donde inciden en la definición de actividades que incrementen la inmersión del jugador en un mundo virtual que favorezca el aprendizaje de diferentes contenidos.

Así pues, se ha podido constatar que existen diferentes ámbitos desde los que se abordan las investigaciones centradas en los videojuegos bélicos en la última década (2010-2020). Ello ha permitido observar que ofrecen una visión poliédrica del objeto de estudio. Sin embargo, la presente revisión sistemática pretende analizar los diseños de investigación adoptados, identificando sus objetivos, instrumentos, procedimientos y resultados más relevantes.

\section{MÉTODO}

\subsection{Objetivo}

El presente trabajo se centra en revisar las investigaciones, publicadas en la década 2010-2020 en el contexto internacional, sobre videojuegos bélicos y educación. La metodología adoptada es cualitativa, concretada en la revisión sistemática de investigaciones, a partir de un meta-análisis, adoptando las pautas de la declaración PRISMA-P2015 (Preferred Reporting Items for Systematic reviews and Meta-Analyses for Protocols 2015) (Moher et al., 2015).

\subsection{Estrategias de búsqueda}

Se hicieron búsquedas selectivas en las bases de datos: SAGE, SCOPUS, Springer LINK, Web of Science, Wiley Online Library, Oxford Journals, Cambridge Journals, Google Scholar y Science Direct, utilizando los términos de búsqueda en español e inglés, entre los cuales se puede mencionar: videojuegos bélicos; videojuegos bélicos y pensamiento crítico; videojuegos e historia; war videogames and education; critical thinking and war videogames; war videogames; videogames and history; war videogames and immersion; videogames and design; ethical analysis and war videogames; war vie deogames and effect. Estos términos se buscaron en títulos, resúmenes y palabras clave (keywords), añadiendo intersecciones y uniones mediante operadores Y, O, AND y OR.

Entre los criterios de selección se consideró que fueran artículos de revistas publicadas en el SJR, tesis o trabajos de máster, en español e inglés, relacionados con los videojuegos bélicos y sus posibles aplicaciones educativas ligadas al desarrollo de competencias históricas, pensamiento crítico, etc.; efectos de estos videojuegos, capacidad inmersiva e implicación de los jugadores; estudios socio-críticos sobre su 
impacto; análisis del diseño técnico, etc. De las 85 investigaciones obtenidas inicialmente, solo se seleccionaron un total de 37 que cumplían los requisitos.

Tabla 1. Fuentes consultadas. Elaboración propia

\begin{tabular}{|l|l|}
\hline \multicolumn{1}{|c|}{ Fuente } & \multicolumn{1}{c|}{ Dirección web } \\
\hline BD SCOPUS & $\underline{\text { https://www.scopus.com/ }}$ \\
\hline Web Of Science & $\underline{\text { https://www.accesowok.fecyt.es/ }}$ \\
\hline Herramientas de Google & $\underline{\text { http://scholar.google.es/ (Google Académico) }}$ \\
\hline $\begin{array}{l}\text { Repositorios documentales (tesis y artículos de } \\
\text { revistas) }\end{array}$ & $\begin{array}{l}\text { http://digital.csic.es/ } \\
\text { http://oatd.org/ }\end{array}$ \\
\hline $\begin{array}{l}\text { Rttps://buo.uniovi.es/ } \\
\text { referenciastas bespecializadas (incorporadas en las }\end{array}$ & \\
\hline
\end{tabular}

Tras su lectura, se clasificaron atendiendo a los diferentes ámbitos desde los que se abordan: a) contextos educativos; b) ámbito experimental-psicológico; c) sociológico y/o antropológico; $y, d$ ) tecnológico. Posteriormente, se identificaron tanto los objetivos, la metodología adoptada (cuantitativa, cualitativa o mixta), el procedimiento seguido, los instrumentos y/o videojuegos bélicos empleados, y los resultados más destacados.

\subsection{Muestra}

Los 37 artículos seleccionados se agrupan en función de los diferentes ámbitos desde los que abordan el estudio de los videojuegos, estableciendo subgrupos atendiendo a matices en función del contenido (Figura 1).

1. Investigaciones aplicadasen contextoseducativos (verdescripción en Tablas 2 y3): - Aplicaciones didácticas y/o desarrollo de competencias (10) (Camarero, 2019; Cuenca \& Martín, 2010; Fisher, 2011; García-González, 2016; Gish, 2010; Holdijck, 2016; Marcano, 2014; O’Neill \& Feenstra, 2016; Unsworth et al., 2015; Watson, Mong \& Harris, 2011).

- Potenciación del espíritu crítico, pensamiento y/o empatía histórica (6) (Alhabash \& Wise, 2015; Boltz, 2017; Burguess et al., 2011; Chapman, 2016; Metzger \& Paxton, 2016; Šisler, 2016).

2. Estudios experimentales de carácter psicológico (ver descripción en Tablas 4 y 5):

- Validación psicométrica de instrumentos (2), para medir la capacidad inmersiva (Cheng, She \& Annetta, 2014) y compromiso e implicación de los jugadores (Zaib, Hool \& Hlavacs, 2016). 


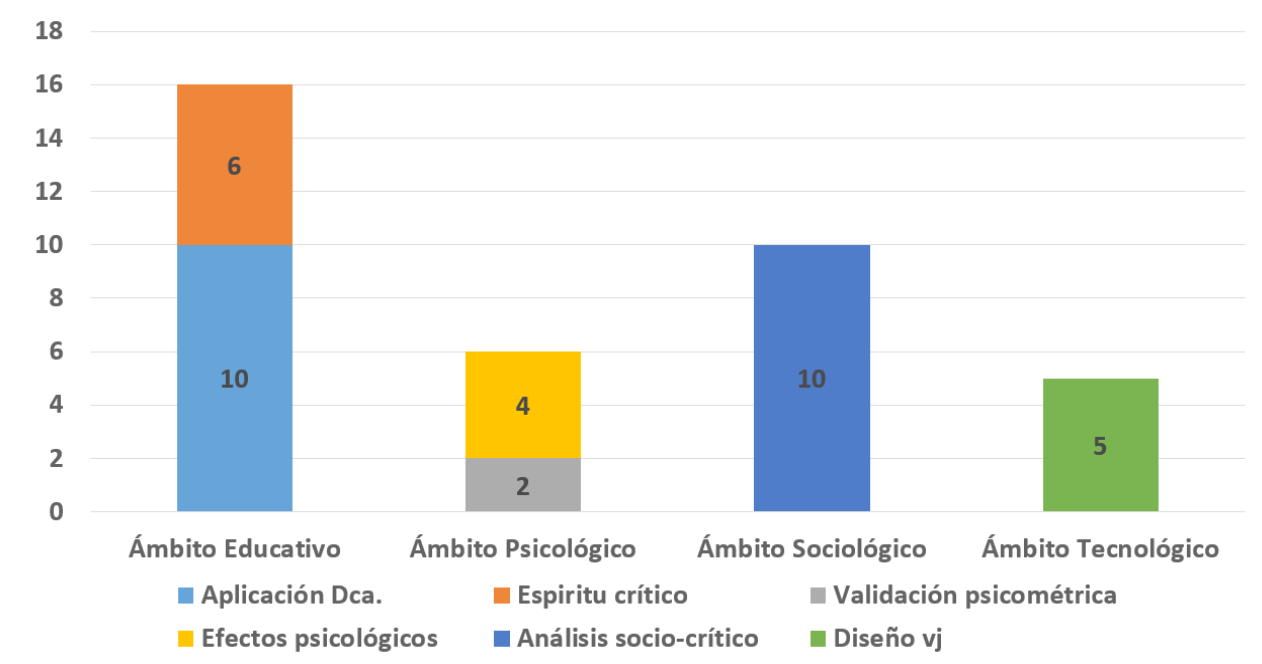

Figura 1. Distribución de las 37 investigaciones atendiendo al ámbito de estudio.

- Estudios sobre efectos de vj en sujetos (4) (Maganuco et al. 2019; Örtqvist \& Liljedahl, 2010; Teng et al., 2019; Weibel \& Wissmath, 2011).

3. Estudios del ámbito sociológico y antropológico (ver descripción en Tabla 6):

Análisis socio-crítico, socio-político y ético de juegos bélicos (10) Donald, 2019; García-Moreno, 2017; González \& Igartua, 2020; Nardone, 2017; Payne, 2014; Robinson, 2012; Robinson \& Schulzke, 2016; Saber \& Webber, 2017; Shaw, 2010; Verino, 2019).

4. Estudios del ámbito tecnológico (ver descripción en Tabla 7):

Análisis del diseño técnico de videojuegos. (5) (De Lope et al., 2017; De Smale, Kors \& Sandovar, 2019; Díaz, 2014; Hanes \& Stone, 2019; Maniega, Yànez \& Lara, 2011).

\section{RESULTADOS}

\subsection{Investigaciones aplicadas en contextos educativos.}

En las tablas 2 y 3 se presenta el análisis del diseño de investigación de los 16 estudios encontrados, de los cuales 10 presentan y/o analizan aplicaciones didácticas de videojuegos bélicos y estudios sobre las oportunidades que presentan para el desarrollo de competencias. Además, se incluyen otros 6 estudios que abordan aspectos 
relacionados con la capacidad de estos juegos para potenciar el pensamiento y espíritu crítico, así como la empatía histórica.

Tabla 2. Estudios sobre videojuegos bélicos (vjb) en contextos educativos: aplicaciones didácticas y/o desarrollo de competencias. Elaboración propia.

\begin{tabular}{|c|c|c|c|}
\hline \multirow{2}{*}{$\begin{array}{l}\text { Estudio } \\
\text { Método }\end{array}$} & \multicolumn{3}{|l|}{ Diseño de la investigación } \\
\hline & Objetivo/s & Procedimiento e instrumento & Resultados \\
\hline $\begin{array}{l}\text { Camarero (2019) } \\
\text { Cualitativo. }\end{array}$ & $\begin{array}{l}\text { - Analizar si el empleo del } \\
\text { Total War: Roma Il activa } \\
\text { el pensamiento histórico } \\
\text { y las competencias bási- } \\
\text { cas en Historia ( } 2^{\circ} \text { ESO). }\end{array}$ & $\begin{array}{l}\text { Diseño de una intervención } \\
\text { educativa en la asignatura } \\
\text { de historia, con posterior } \\
\text { cuestionario para constatar los } \\
\text { conocimientos adquiridos. }\end{array}$ & $\begin{array}{l}\text { - Los alumnos asimilaron } \\
\text { los contenidos de historia } \\
\text { satisfactoriamente. } \\
\text { - Se incrementó la motivación } \\
\text { al interactuar. }\end{array}$ \\
\hline $\begin{array}{l}\text { Cuenca y Mar- } \\
\text { tín (2010). } \\
\text { Cualitativo. }\end{array}$ & $\begin{array}{l}\text { - Describir cómo utilizar } \\
\text { vjb en el aula para } \\
\text { fomentar la reflexión. } \\
\text { - Constatar lo que } \\
\text { aprenden alumnos a } \\
\text { partir de sus estrategias } \\
\text { para solucionar conflic- } \\
\text { tos bélicos. }\end{array}$ & $\begin{array}{l}\text { Clasifican } 35 \text { vjb y analizan su } \\
\text { potencial didáctico en Prima- } \\
\text { ria y Secundaria. Utilizan Age } \\
\text { of Empires y Empire Earth en } \\
\text { geografía, historia y econo- } \\
\text { mía. Se crea una batería de } \\
\text { preguntas para constatar los } \\
\text { aprendizajes. }\end{array}$ & $\begin{array}{l}\text { - Aportan una metodología } \\
\text { para incluir los vjb en el aula } \\
\text { primando la reflexión sobre } \\
\text { las ejecuciones y estrategias } \\
\text { para solucionar conflictos } \\
\text { bélicos. } \\
\text { - Se constatan los apren- } \\
\text { dizajes adquiridos a nivel } \\
\text { conceptual, procedimental y } \\
\text { actitudinal. }\end{array}$ \\
\hline $\begin{array}{l}\text { Fisher (2011) } \\
\text { Cualitativo }\end{array}$ & $\begin{array}{l}\text { - Constatar los apren- } \\
\text { dizajes tangenciales } \\
\text { adquiridos por alumnado } \\
\text { (K12) al usar Medal of } \\
\text { Honor: European Assault y } \\
\text { Call of Duty: World at War } \\
\text { para interpretar y analizar } \\
\text { la II GM. }\end{array}$ & $\begin{array}{l}\text { Los alumnos juegan con los } \\
\text { videojuegos y aprenden los } \\
\text { contenidos sobre la IIGM. } \\
\text { Efectúan entrevistas semies- } \\
\text { tructuradas para analizar los } \\
\text { aprendizajes adquiridos por } \\
\text { los jugadores sobre la IIGM. }\end{array}$ & $\begin{array}{l}\text { - Estos vjb FPS de la II GM } \\
\text { dotan de experiencias envol- } \\
\text { ventes para aprender historia. } \\
\text { - Ayudan a disipar mitos histó- } \\
\text { ricos y malas interpretaciones, } \\
\text { o analizar su precisión históri- } \\
\text { ca, promoviendo el desarrollo } \\
\text { de la investigación crítica, } \\
\text { el análisis comparativo, etc. }\end{array}$ \\
\hline \multicolumn{2}{|c|}{$\begin{array}{l}\text { García-González (2016) } \\
\text { Cualitativo } \\
\text { Diseñar un método didáctico para abordar } \\
\text { la guerra en su contexto histórico, activando } \\
\text { el espíritu crítico con vjb. }\end{array}$} & $\begin{array}{l}\text { Se estudia la guerra utilizando } \\
\text { vjb, incidiendo en variables } \\
\text { científico-tecnológicas y datos } \\
\text { sobre otras dimensiones. }\end{array}$ & $\begin{array}{l}\text { Los vjb estimulan el espíritu } \\
\text { crítico y las competencias } \\
\text { históricas del alumnado al } \\
\text { analizar la realidad de los } \\
\text { conflictos bélicos. }\end{array}$ \\
\hline $\begin{array}{l}\text { Gish (2010) } \\
\text { Cualitativo: } \\
\text { Análisis de } \\
\text { contenido. }\end{array}$ & $\begin{array}{l}\text { Analizar la represen- } \\
\text { tación de la historia, la } \\
\text { guerra y la violencia de } \\
\text { la GM Il en la saga Call } \\
\text { of Duty. }\end{array}$ & $\begin{array}{l}\text { Se estudia cómo la saga Call } \\
\text { of Duty muestra la guerra, la } \\
\text { violencia y la historia de la GM } \\
\text { Il en sus escenas cinemáticas y } \\
\text { situaciones jugables mediante } \\
\text { el impacto emocional. }\end{array}$ & $\begin{array}{l}\text { El juego exige al usuario } \\
\text { cometer actos violentos para } \\
\text { avanzar en la historia. Ofrece } \\
\text { una visión reduccionista de la } \\
\text { guerra, subrayando los actos } \\
\text { violentos. }\end{array}$ \\
\hline $\begin{array}{l}\text { Holdijk (2016) } \\
\text { Cualitativo: } \\
\text { Estudio de } \\
\text { casos. }\end{array}$ & $\begin{array}{l}\text { - Valorar las aportaciones } \\
\text { históricas de los vjb. } \\
\text { - Fomentar la colabora- } \\
\text { ción de historiadores en } \\
\text { el diseño de vjb. }\end{array}$ & $\begin{array}{l}\text { Se analizan las fortalezas histó- } \\
\text { ricas plasmadas en los video- } \\
\text { juegos sobre la IGM mediante } \\
\text { el análisis de contenido. }\end{array}$ & $\begin{array}{l}\text { Algunos vjb pueden ser útiles } \\
\text { para enseñar aspectos de la } \\
\text { IGM. Si los contenidos estuvie- } \\
\text { ran asesorados por historia- } \\
\text { dores ganarían en fiabilidad. }\end{array}$ \\
\hline
\end{tabular}




\begin{tabular}{|c|c|c|c|}
\hline $\begin{array}{l}\text { Marcano (2014) } \\
\text { Cuantitativo: } \\
\text { Descriptivo. }\end{array}$ & $\begin{array}{l}\text { - Identificar el impacto } \\
\text { emocional de los vjb. } \\
\text { - Saber las motivaciones } \\
\text { de los usuarios para } \\
\text { jugar. } \\
\text { - Conocer los perfiles } \\
\text { de jugador y constatar } \\
\text { diferencias por género, } \\
\text { edad y nacionalidad } \\
\text { al interaccionar con el } \\
\text { videojuego. } \\
\text { - Conocer las compe- } \\
\text { tencias activadas con } \\
\text { Call of Duty y su valor } \\
\text { formativo. }\end{array}$ & $\begin{array}{l}\text { Cuestionario de } 32 \text { ítems } \\
\text { recoge la opinión (N=665) } \\
\text { sobre: los gráficos, realismo, } \\
\text { jugabilidad, emoción, reto, } \\
\text { diversión, fantasía, interac- } \\
\text { ción social, competición, } \\
\text { aprendizaje emocional, } \\
\text { de historia y tecnología. } \\
\text { Apoyado en la escala de usos } \\
\text { y gratificaciones de los vj } \\
\text { (Sherry, Lucas, Greenberg \& } \\
\text { Lachlan, 2006). } \\
\text { Aplicación online y análisis. }\end{array}$ & $\begin{array}{l}\text { - Suscitan miedo a morir, } \\
\text { angustia ante las amenazas, } \\
\text { incertidumbre ante los } \\
\text { enemigos. } \\
\text { - Les motiva la satisfac- } \\
\text { ción por los logros, ser los } \\
\text { mejores, interacción social, } \\
\text { gráficos y jugabilidad, retos } \\
\text { atractivos, fantasía, aprendi- } \\
\text { zaje y diversión. } \\
\text {-Perfil:estudiantessintrabajo. } \\
\text { - Mujeres priman el trabajo } \\
\text { en equipo. Los <21 ponde- } \\
\text { ran la fantasía y la autosu- } \\
\text { peración. Los españoles: el } \\
\text { intercambio social y los lati- } \\
\text { nos, jugabilidad y gráficos. } \\
\text { - Fortalece la senso-percep- } \\
\text { ción y motricidad fina, la } \\
\text { competencia social al jugar } \\
\text { en equipo, tolerancia hacia } \\
\text { las debilidades y diferencias. }\end{array}$ \\
\hline $\begin{array}{l}\text { Unsworth et al. } \\
\text { (2015) } \\
\text { Cuantitativo: } \\
\text { Descriptivo. }\end{array}$ & $\begin{array}{l}\text { Analizar la relación } \\
\text { entre la experiencia pro- } \\
\text { porcionada por vj y las } \\
\text { habilidades cognitivas. }\end{array}$ & $\begin{array}{l}\text { Se analiza con un cuestio- } \\
\text { nario el posible incremento } \\
\text { de las habilidades cognitivas } \\
\text { (memoria, inteligencia y } \\
\text { atención) de } 252 \text { universita- } \\
\text { rios tras jugar con un vj. }\end{array}$ & $\begin{array}{l}\text { La relación entre vj y desa- } \\
\text { rrollo de habilidades cogni- } \\
\text { tivas es débil o inexistente, } \\
\text { luego la experiencia que } \\
\text { proporcionan los vj no acti- } \\
\text { va habilidades cognitivas. }\end{array}$ \\
\hline $\begin{array}{l}\text { O’Neil y Feens- } \\
\text { tra (2016) } \\
\text { Estudio de } \\
\text { casos. }\end{array}$ & $\begin{array}{l}\text { Estudiar si los conteni- } \\
\text { dos históricos de vjb } \\
\text { son veraces y fiables. }\end{array}$ & $\begin{array}{l}\text { Los jugadores }(\mathrm{N}=12) \text { del } \\
\text { Medal of Honor: Frontline, } \\
\text { responden un cuestionario } \\
\text { sobre lo aprendido, y señalan } \\
\text {-en una entrevista- si lo visto } \\
\text { lo consideran confiable. }\end{array}$ & $\begin{array}{l}\text { El vjb ofrece datos fiables } \\
\text { y actúa como herramienta } \\
\text { motivadora para conocer } \\
\text { hechos históricos y poten- } \\
\text { ciar la empatía con víctimas. }\end{array}$ \\
\hline $\begin{array}{l}\text { Watson, Mong y } \\
\text { Harris (2011) } \\
\text { Estudio de } \\
\text { casos. }\end{array}$ & $\begin{array}{l}\text { Analizar si el uso de un } \\
\text { serious games sobre IIGM } \\
\text { favorece la enseñanza } \\
\text { y el aprendizaje de la } \\
\text { historia en secundaria. }\end{array}$ & $\begin{array}{l}\text { Se explicó la IIGM y el alumna- } \\
\text { do jugó al videojuego Making } \\
\text { History. } \\
\text { Se constató si había una } \\
\text { mayor predisposición al apren- } \\
\text { dizaje con el videojuego. }\end{array}$ & $\begin{array}{l}\text { El videojuego Making History } \\
\text { favoreció la actividad y el } \\
\text { compromiso del alumnado. } \\
\text { Y favoreció el desarrollo de } \\
\text { estrategias para maximizar el } \\
\text { aprendizaje. }\end{array}$ \\
\hline
\end{tabular}


Tabla 3. Estudios sobre vj en contextos educativos orientados a potenciar el espíritu crítico, pensamiento y/o empatía histórica. Elaboración propia.

\begin{tabular}{|c|c|c|c|}
\hline \multirow{2}{*}{$\begin{array}{l}\text { Estudio y } \\
\text { Método }\end{array}$} & \multicolumn{3}{|l|}{ Diseño de la investigación } \\
\hline & Objetivo/s & Procedimiento e instrumento & Resultados \\
\hline $\begin{array}{l}\text { Alhabash y Wise } \\
\text { (2015) } \\
\text { Cuantitativo: } \\
\text { cuasi-experi- } \\
\text { mental. }\end{array}$ & \begin{tabular}{|l|} 
Analizar los cambios \\
de actitud de alumnos \\
$(\mathrm{N}=68)$ derivados del \\
efecto de un serious game \\
sobre guerra.
\end{tabular} & $\begin{array}{l}\text { El alumnado realizó un pretest } \\
\text { y postest sobre actitudes hacia } \\
\text { israelíes y palestinos para } \\
\text { constatar los cambios pro- } \\
\text { vocados por el serious game } \\
\text { Peacemaker. }\end{array}$ & $\begin{array}{l}\text { El juego ayudó a cambiar la } \\
\text { actitud del alumnado frente } \\
\text { a colectivos estigmatizados: } \\
\text { israelíes y palestinos. }\end{array}$ \\
\hline $\begin{array}{l}\text { Boltz (2017) } \\
\text { Cualitativo: } \\
\text { Estudio de casos }\end{array}$ & $\begin{array}{l}\text { Examinar cómo se } \\
\text { promueve la empatía } \\
\text { histórica en el vjb Valiant } \\
\text { Hearts. }\end{array}$ & $\begin{array}{l}\text { Se entrevistó a } 4 \text { sujetos y se } \\
\text { les sometió a un pre-test y un } \\
\text { post-test sobre estereotipos, } \\
\text { precisión histórica e implica- } \\
\text { ción emocional con la historia } \\
\text { narrada en el vjb Valiant } \\
\text { Hearts. }\end{array}$ & $\begin{array}{l}\text { Se identifican las dimensio- } \\
\text { nes que promueve el juego } \\
\text { ligadas a la empatía histórica: } \\
\text { contextualización, perspecti- } \\
\text { va, conexión afectiva. }\end{array}$ \\
\hline $\begin{array}{l}\text { Burguess et al. } \\
\text { (2011) } \\
\text { Mixto: Cuali- } \\
\text { tativo: análisis } \\
\text { de contenido } \\
\text { y cuantitativo: } \\
\text { descriptivo. }\end{array}$ & $\begin{array}{l}\text { Demostrar la existencia } \\
\text { de estereotipos raciales y } \\
\text { de género en los vjb. }\end{array}$ & $\begin{array}{l}\text { Se realizó un análisis de los es- } \\
\text { tereotipos raciales y de género } \\
\text { plasmados en los protagonis- } \\
\text { tas }(\mathrm{N}=149) \text { de vjb. } \\
\text { Se preguntó a } 39 \text { universi- } \\
\text { tarios cómo ven a dichos } \\
\text { protagonistas. }\end{array}$ & $\begin{array}{l}\text { Hay pocas mujeres y perso- } \\
\text { najes de color. No hay negros } \\
\text { en conflictos bélicos históri- } \\
\text { cos. Los sujetos relacionan a } \\
\text { los personajes de color con } \\
\text { armas. }\end{array}$ \\
\hline $\begin{array}{l}\text { Chapman (2016) } \\
\text { Cualitativo: } \\
\text { Análisis de } \\
\text { contenido. }\end{array}$ & $\begin{array}{l}\text { Explorar la relación entre } \\
\text { la visión de la IGM } \\
\text { ofrecida por los vjb y la } \\
\text { memoria colectiva. }\end{array}$ & $\begin{array}{l}\text { Se analizaron } 58 \text { vjb relaciona- } \\
\text { dos con la IGM, que abordan } \\
\text { los problemas éticos derivados } \\
\text { de mostrar la guerra como un } \\
\text { entretenimiento. }\end{array}$ & $\begin{array}{l}\text { Estos vjb aportan datos } \\
\text { históricos y fidelidad en } \\
\text { los emplazamientos. Pero } \\
\text { omiten aspectos históricos: } \\
\text { las causas y repercusiones de } \\
\text { la guerra. }\end{array}$ \\
\hline $\begin{array}{l}\text { Metzger y Pax- } \\
\text { ton (2016) } \\
\text { Cualitativo Análi- } \\
\text { sis de contenido }\end{array}$ & $\begin{array}{l}\text { Crear un modelo para } \\
\text { enseñar historia con vjb, } \\
\text { analizando la inclusión } \\
\text { de elementos históricos } \\
\text { para facilitar a los juga- } \\
\text { dores la interacción con } \\
\text { el pasado y su interpre- } \\
\text { tación. }\end{array}$ & $\begin{array}{l}\text { Se analizaron vjb históri- } \\
\text { cos, teorizando sobre las } \\
\text { interacciones entre su diseño, } \\
\text { la respuesta del jugador, el } \\
\text { pensamiento histórico y las } \\
\text { representaciones históricas } \\
\text { que recrean. }\end{array}$ & $\begin{array}{l}\text { Elaboran un vocabulario } \\
\text { útil para investigadores y } \\
\text { educadores que potencia el } \\
\text { aprendizaje de la historia, } \\
\text { rescatando el potencial for- } \\
\text { mativo de estos videojuegos. }\end{array}$ \\
\hline $\begin{array}{l}\text { Šisler (2016) } \\
\text { Cualitativa. } \\
\text { Estudio de caso } \\
\text { único }\end{array}$ & $\begin{array}{l}\text { Analizar la autentici- } \\
\text { dad de la historia y la } \\
\text { guerra en el videojuego } \\
\text { Czechoslovakia 38-89: } \\
\text { Assassination. }\end{array}$ & $\begin{array}{l}\text { Se analizó la historia del vi- } \\
\text { deojuego Czechoslovakia 38- } \\
\text { 89: Assassination, valorando } \\
\text { su contextualización, la cons- } \\
\text { trucción del relato e inclusión } \\
\text { de elementos reales. }\end{array}$ & $\begin{array}{l}\text { Se detecta un sesgo reduc- } \\
\text { cionista y mecanicista sobre } \\
\text { la representación de la } \\
\text { historia y la guerra. }\end{array}$ \\
\hline
\end{tabular}


Revisión sistemática de investigaciones...-M.E. del Moral y C. Rodríguez

\subsection{Estudios experimentales de carácter psicológico}

En las tablas 4 y 5 , se analiza el diseño de investigación de los estudios de carácter psicológico hallados. Dos centrados en la validación psicométrica de instrumentos para medir la capacidad inmersiva e implicación de los jugadores. Los cuatro restantes focalizados en el análisis de los efectos que los videojuegos producen en los sujetos.

Tabla 4. Estudios experimentales ligados a los videojuegos: validación psicométrica de instrumentos. Elaboración propia.

\begin{tabular}{|c|c|c|c|}
\hline \multirow{2}{*}{$\begin{array}{l}\text { Estudio y } \\
\text { Método }\end{array}$} & \multicolumn{3}{|l|}{ Diseño de la investigación } \\
\hline & Objetivo/s & $\begin{array}{l}\text { Procedimiento e instru- } \\
\text { mento }\end{array}$ & Resultados \\
\hline $\begin{array}{l}\text { Cheng, She y } \\
\text { Annetta (2014) } \\
\text { Cuantitativo. }\end{array}$ & $\begin{array}{l}\text { - Crear un instrumento para } \\
\text { medir la capacidad inmersi- } \\
\text { va de vj. } \\
\text { - Relacionar la capacidad } \\
\text { inmersiva del vj con el } \\
\text { aprendizaje que promueve } \\
\text { (test-postest). }\end{array}$ & $\begin{array}{l}\text { Se constató la capacidad } \\
\text { inmersiva del el serious game } \\
\text { Virtual Age con el cuestio- } \\
\text { nario GIQ. } \\
\text { Se analizó su impacto en el } \\
\text { aprendizaje de } 260 \text { sujetos } \\
\text { con un pretest y un postest } \\
\text { sobre conocimientos. }\end{array}$ & $\begin{array}{l}\text { La capacidad inmersiva del } \\
\text { vj favoreció la adquisición de } \\
\text { los conocimientos aborda- } \\
\text { dos en el vj. }\end{array}$ \\
\hline $\begin{array}{l}\text { Zaib, Hool y } \\
\text { Hlavacs (2016) } \\
\text { Cuantitativo. }\end{array}$ & $\begin{array}{l}\text { Crear y validar un instru- } \\
\text { mento multidimensional } \\
\text { para medir el compromiso o } \\
\text { permanencia de los jugado- } \\
\text { res en videojuegos. }\end{array}$ & $\begin{array}{l}\text { Se validó y analizó la fiabili- } \\
\text { dad de distintos indicado- } \\
\text { res asociados a } 3 \text { factores: } \\
\text { cognitivos, afectivos y } \\
\text { conductuales. Mediante } \\
\text { un análisis exploratorio, y } \\
\text { posterior análisis factorial } \\
\text { confirmatorio. }\end{array}$ & $\begin{array}{l}\text { El compromiso de los } \\
\text { jugadores consta de varias } \\
\text { dimensiones que implican } \\
\text { aspectos: cognitivos, afecti- } \\
\text { vos, y conductuales. }\end{array}$ \\
\hline
\end{tabular}

Tabla 5. Estudios experimentales centrados en los efectos de los videojuegos en los sujetos. Elaboración propia.

\begin{tabular}{|c|c|c|c|}
\hline \multirow{2}{*}{$\begin{array}{l}\text { Estudio y } \\
\text { Método }\end{array}$} & \multicolumn{3}{|l|}{ Diseño de la investigación } \\
\hline & Objetivo/s & $\begin{array}{l}\text { Procedimiento e instru- } \\
\text { mento }\end{array}$ & Resultados \\
\hline $\begin{array}{l}\text { Maganuco et al. } \\
\text { (2019). } \\
\text { Cuantitativo. }\end{array}$ & $\begin{array}{l}\text { Explorar la relación entre las } \\
\text { respuestas emocionales e } \\
\text { impulsividad de los jugado- } \\
\text { res de MMORPG con su nivel } \\
\text { de adicción. }\end{array}$ & $\begin{array}{l}\text { Se sometió al test de adic- } \\
\text { ción a internet (PIU) a juga- } \\
\text { dores adultos de MMORPG } \\
(\mathrm{N}=364) \text {. }\end{array}$ & $\begin{array}{l}\text { Se detectó el riesgo de de- } \\
\text { sarrollar patrones adictivos } \\
\text { debido a la distracción con } \\
\text { los estímulos novedosos } \\
\text { y atractivos propios de los } \\
\text { videojuegos. }\end{array}$ \\
\hline $\begin{array}{l}\text { Örtqvist y } \\
\text { Liljedahl (2010). } \\
\text { Cuantitativo. }\end{array}$ & $\begin{array}{l}\text { Relacionar la influencia } \\
\text { entre los rasgos de los } \\
\text { jugadores, su capacidad } \\
\text { inmersiva y sus experien- } \\
\text { cias de juego. }\end{array}$ & $\begin{array}{l}\text { Se empleó un cuestiona- } \\
\text { rio de escala Likert para } \\
\text { conocer la inmersión y la } \\
\text { experiencia de juego de los } \\
\text { usuarios }(\mathrm{N}=48)\end{array}$ & $\begin{array}{l}\text { La inmersión en el juego } \\
\text { influye en la experiencia } \\
\text { lúdica de los usuarios y el } \\
\text { perfil de éstos en su capaci- } \\
\text { dad inmersiva. }\end{array}$ \\
\hline
\end{tabular}




\begin{tabular}{|c|c|c|c|}
\hline $\begin{array}{l}\text { Teng et al. } \\
\text { (2019). } \\
\text { Cuantitativo. }\end{array}$ & $\begin{array}{l}\text { Estudiar en qué medida la } \\
\text { exposición a videojuegos } \\
\text { violentos fomentan la } \\
\text { desconexión moral en los } \\
\text { adolescentes chinos. }\end{array}$ & $\begin{array}{l}\text { Miden el nivel de tolerancia } \\
\text { de adolescentes ( } \mathrm{N}=1340) \\
\text { expuestos a vj violentos y } \\
\text { su grado de desconexión } \\
\text { moral, } \\
3 \text { veces cada } 6 \text { meses. }\end{array}$ & $\begin{array}{l}\text { Los comportamientos } \\
\text { inmorales (robar, matar...) } \\
\text { son tolerados en mayor } \\
\text { medida por los adolescen- } \\
\text { tes más jóvenes indepen- } \\
\text { dientemente del género. }\end{array}$ \\
\hline $\begin{array}{l}\text { Weibel y Wiss- } \\
\text { math (2011). } \\
\text { Mixto. }\end{array}$ & $\begin{array}{l}\text { Relacionar la presencia } \\
\text { e implicación de los } \\
\text { sujetos en vj con su poder } \\
\text { inmersivo, analizando su } \\
\text { influencia en el rendimien- } \\
\text { to y disfrute. }\end{array}$ & $\begin{array}{l}\text { Se analiza la capacidad } \\
\text { inmersiva y motivación de } \\
120 \text { usuarios, tras jugar con } \\
\text { Neverwinter Nights, Formula } \\
1 \text { y Sonic The Hedgehog, con } \\
\text { un cuestionario. }\end{array}$ & $\begin{array}{l}\text { La presencia o sensación } \\
\text { del sujeto de estar en un } \\
\text { mundo ficticio, no se rela- } \\
\text { ciona con la implicación o } \\
\text { las ejecuciones de éste en } \\
\text { el juego. }\end{array}$ \\
\hline
\end{tabular}

\subsection{Investigaciones ligadas ámbito sociológico y antropológico}

En la tabla 6 se presentan el análisis del diseño de diez investigaciones desde un enfoque socio-crítico y ético sobre los videojuegos bélicos.

Tabla 6. Estudios centrados en el análisis socio-crítico, socio-político y ético de juegos bélicos. Elaboración propia.

\begin{tabular}{|c|c|c|c|}
\hline \multirow{2}{*}{$\begin{array}{l}\text { Estudio y } \\
\text { Método }\end{array}$} & \multicolumn{3}{|l|}{ Diseño de la investigación } \\
\hline & Objetivo/s & $\begin{array}{l}\text { Procedimiento e instru- } \\
\text { mento }\end{array}$ & Resultados \\
\hline $\begin{array}{l}\text { Donald (2019) } \\
\text { Análisis descrip- } \\
\text { tivo. }\end{array}$ & $\begin{array}{l}\text { Explorar cómo se representa } \\
\text { concibe la guerra justa en los } \\
\text { videojuegos bélicos. }\end{array}$ & $\begin{array}{l}\text { Se hizo un recorrido por dis- } \\
\text { tintos vjb para analizar cómo } \\
\text { se muestra la guerra. }\end{array}$ & $\begin{array}{l}\text { Los vjb son realistas en } \\
\text { términos de equipamiento y } \\
\text { precisión ambiental, pero no } \\
\text { evocan emociones y senti- } \\
\text { mientos como el cine. }\end{array}$ \\
\hline $\begin{array}{l}\text { García-Moreno } \\
(2017) \\
\text { Cualitativo. }\end{array}$ & $\begin{array}{l}\text { - Analizar la Guerra Fría en } \\
\text { vjb: referencias históricas y } \\
\text { estrategias narrativas. } \\
\text { - Estudiar la construcción y } \\
\text { relación de personajes. }\end{array}$ & $\begin{array}{l}\text { Se recopiló información re- } \\
\text { ferente a la Guerra Fría en la } \\
\text { saga Metal Gear y a través de } \\
\text { una ficha, se identificó y cla- } \\
\text { sificó cada título de la saga } \\
\text { atendiendo a la narratología } \\
\text { y a la ludología. }\end{array}$ & $\begin{array}{l}\text { La saga guarda estrecha re- } \\
\text { lación con la reconstrucción } \\
\text { histórica. } \\
\text { Los personajes representan } \\
\text { figuras históricas enfrenta- } \\
\text { das y reflejan el panorama } \\
\text { internacional de la Guerra } \\
\text { Fría, mostrando una visión } \\
\text { crítica. }\end{array}$ \\
\hline $\begin{array}{l}\text { González e } \\
\text { lgartua (2020) } \\
\text { Mixto. }\end{array}$ & $\begin{array}{l}\text { Establecer una base } \\
\text { empírica para construir las } \\
\text { creencias y actitudes de los } \\
\text { usuarios mediante la teoría } \\
\text { del cultivo. }\end{array}$ & $\begin{array}{l}\text { Se analizan vjb }(\mathrm{N}=62) \text { y se } \\
\text { categorizaron atendiendo } \\
\text { a su narrativa, participación } \\
\text { de los protagonistas y efecto } \\
\text { de guerra en las relaciones } \\
\text { entre los personajes. }\end{array}$ & $\begin{array}{l}\text { Se apela a la defensa para le- } \\
\text { gitimar los conflictos, no hay } \\
\text { motivaciones territoriales } \\
\text { ni presencia de civiles. Los } \\
\text { protagonistas adoptan un } \\
\text { perfil heroico e invulnerable } \\
\text { al daño. }\end{array}$ \\
\hline
\end{tabular}




\begin{tabular}{|c|c|c|c|}
\hline $\begin{array}{l}\text { Nardone (2017) } \\
\text { Cualitativo. }\end{array}$ & $\begin{array}{l}\text { Realizar una revisión de } \\
\text { los paradigmas éticos y } \\
\text { políticos representados en } \\
\text { los videojuegos. }\end{array}$ & $\begin{array}{l}\text { Se analizan una serie de ar- } \\
\text { tículos relacionados con la } \\
\text { violencia y los videojuegos, } \\
\text { para extraer los resultados } \\
\text { más relevantes. }\end{array}$ & $\begin{array}{l}\text { Los videojuegos son una } \\
\text { extensión del mundo real. } \\
\text { Las víctimas no son huma- } \\
\text { nas y la muerte es ficción. } \\
\text { Se caricaturiza la violencia } \\
\text { con riesgo a perder su } \\
\text { dramatismo. }\end{array}$ \\
\hline $\begin{array}{l}\text { Payne (2014) } \\
\text { Cualitativo } \\
\text { Estudio de caso } \\
\text { único. }\end{array}$ & $\begin{array}{l}\text { Analizar cómo se abordan } \\
\text { los efectos y consecuencias } \\
\text { éticas de una intervención } \\
\text { bélica en un vjb, determi- } \\
\text { nando la existencia de una } \\
\text { disonancia narrativa. }\end{array}$ & $\begin{array}{l}\text { Se analizan los aspectos } \\
\text { jugables y narrativos del } \\
\text { videojuego Spec Ops: The } \\
\text { Line, centrándose en las } \\
\text { consecuencias éticas de } \\
\text { las ejecuciones de los } \\
\text { personajes, comparándolo } \\
\text { con otros vjb como la saga } \\
\text { Call of Duty. }\end{array}$ & $\begin{array}{l}\text { El vj hace reflexionar en } \\
\text { cada decisión, provocando } \\
\text { un sentimiento de culpabi- } \\
\text { lidad y no disfrute. No hay } \\
\text { disonancia narrativa, es } \\
\text { coherente entre los actos } \\
\text { y las consecuencias éticas } \\
\text { derivadas de los actos de } \\
\text { guerra. }\end{array}$ \\
\hline $\begin{array}{l}\text { Robinson (2012) } \\
\text { Revisión. }\end{array}$ & $\begin{array}{l}\text { Analizar los usos de vj } \\
\text { bélicos para cuestionar } \\
\text { la militarización de la } \\
\text { sociedad. }\end{array}$ & $\begin{array}{l}\text { Se realizó una revisión de } \\
\text { artículos relacionados con } \\
\text { los vjb, para analizar la } \\
\text { capacidad persuasiva de } \\
\text { estos respecto a la milita- } \\
\text { rización. }\end{array}$ & $\begin{array}{l}\text { Los vjb limitan la visión } \\
\text { crítica de la guerra y la } \\
\text { militarización. Es necesa- } \\
\text { rio vj con mecánicas que } \\
\text { promuevan estrategias no } \\
\text { violentas. }\end{array}$ \\
\hline $\begin{array}{l}\text { Robinson y } \\
\text { Schulzke (2016). } \\
\text { Mixto. }\end{array}$ & $\begin{array}{l}\text { Analizar desde una pers- } \\
\text { pectiva política el impacto } \\
\text { de la publicidad de los } \\
\text { vj bélicos en los medios } \\
\text { sociales para aceptar el } \\
\text { militarismo. }\end{array}$ & $\begin{array}{l}\text { Analizan anuncios de vjb } \\
\text { en medios sociales y su } \\
\text { contribución para recono- } \\
\text { cer los focos conflictivos, } \\
\text { los estereotipos de género, } \\
\text { las tecnologías utilizadas, } \\
\text { las nacionalidades, los con- } \\
\text { flictos entre naciones, etc. }\end{array}$ & $\begin{array}{l}\text { El impacto de la publicidad } \\
\text { de vjb y las noticias de gue- } \\
\text { rra en los medios sociales } \\
\text { modelan la percepción de } \\
\text { los ciudadanos frente al } \\
\text { militarismo y la acepta- } \\
\text { ción del intervencionismo } \\
\text { militar. }\end{array}$ \\
\hline $\begin{array}{l}\text { Saber y Webber } \\
\text { ( } 2017 \\
\text { Estudio de caso } \\
\text { único. }\end{array}$ & $\begin{array}{l}\text { Examinar las claves ideoló- } \\
\text { gicas terroristas de Hezbolá } \\
\text { y del Estado Islámico que } \\
\text { inspiran a Special Force 1-2 }\end{array}$ & $\begin{array}{l}\text { Se analizan la autoría, el } \\
\text { diseño narrativo, los perso- } \\
\text { najes, la audiencia a la que } \\
\text { se dirigen los videojuegos } \\
\text { bélicos Special Force } 1 \text { y } 2 \text {. }\end{array}$ & $\begin{array}{l}\text { El sesgo ideológico de es- } \\
\text { tos vjb responde al origen } \\
\text { cultural de los autores y de } \\
\text { la audiencia. Apuestan por } \\
\text { la guerra y los actos bélicos } \\
\text { como actos de defensa. }\end{array}$ \\
\hline $\begin{array}{l}\text { Shaw (2010) } \\
\text { Cuantitativa } \\
\text { Estudio descrip- } \\
\text { tivo. }\end{array}$ & $\begin{array}{l}\text { Constatar cómo la estética } \\
\text { de los vj bélicos contribuye } \\
\text { a propagar la cultura mili- } \\
\text { tarista y el reclutamiento } \\
\text { militar. }\end{array}$ & $\begin{array}{l}\text { Se teoriza acerca del } \\
\text { significado de "jugar", y } \\
\text { se analizan los factores } \\
\text { estéticos que priman en los } \\
\text { juegos de entrenamiento } \\
\text { militar para favorecer el } \\
\text { reclutamiento militar. }\end{array}$ & $\begin{array}{l}\text { Los vjb son espacios de } \\
\text { transición instrumental que } \\
\text { ubican con realismos los } \\
\text { escenarios geográficos de } \\
\text { guerra. Priman el patriotis- } \\
\text { mo y el reclutamiento. }\end{array}$ \\
\hline $\begin{array}{l}\text { Verino (2019) } \\
\text { Cualitativa. } \\
\text { Estudio de Caso. }\end{array}$ & $\begin{array}{l}\text { Analizar los discursos narra- } \\
\text { tivos, elementos artísticos y } \\
\text { el contexto descrito en Call } \\
\text { of Duty. }\end{array}$ & $\begin{array}{l}\text { Se realizó una lectura } \\
\text { analítica del contexto histó- } \\
\text { rico de la saga Call of Duty } \\
(C O D) \text {, sobre la IIGM. }\end{array}$ & $\begin{array}{l}\text { CoD combina la presen- } \\
\text { tación histórica con ima- } \\
\text { ginarios de los jugadores. } \\
\text { Ofrece una visión sesgada } \\
\text { del conflicto, omite la pre- } \\
\text { sencia de civiles y su dolor. }\end{array}$ \\
\hline
\end{tabular}




\subsection{Estudios del ámbito tecnológico.}

En la Tabla 7, se presentan cinco investigaciones, unos analizan los diseños de videojuegos o serious games que aborden situaciones bélicas, y otros presentan modelos de gamificación para favorecer el aprendizaje de contenidos históricos.

Tabla 7. Estudios centrados en el análisis del diseño técnico de videojuegos. Elaboración propia.

\begin{tabular}{|c|c|c|c|}
\hline \multirow{2}{*}{$\begin{array}{l}\text { Estudio y } \\
\text { Método }\end{array}$} & \multicolumn{3}{|l|}{ Diseño de la investigación } \\
\hline & Objetivo/s & $\begin{array}{l}\text { Procedimiento e instru- } \\
\text { mento }\end{array}$ & Resultados \\
\hline $\begin{array}{l}\text { De Lope et al. } \\
\text { (2017). } \\
\text { Cualitativo. }\end{array}$ & $\begin{array}{l}\text { Establecer pautas para di- } \\
\text { señar serious games desde } \\
\text { la teoría de la usabilidad y } \\
\text { jugabilidad. }\end{array}$ & $\begin{array}{l}\text { Se apuesta por incorporar } \\
\text { mecánicas y dinámicas que } \\
\text { favorezcan la jugabilidad y } \\
\text { atraigan a los jugadores. }\end{array}$ & $\begin{array}{l}\text { Debe optarse por una } \\
\text { jugabilidad atractiva que } \\
\text { vertebre los objetivos } \\
\text { educativos y dote de moti- } \\
\text { vación al serious game. }\end{array}$ \\
\hline $\begin{array}{l}\text { De Smale, Kors, y } \\
\text { Sandovar (2019). } \\
\text { Cualitativo: } \\
\text { Estudio de caso. }\end{array}$ & $\begin{array}{l}\text { Analizar el diseño de un } \\
\text { videojuego bélico que con- } \\
\text { juga aspectos argumentales } \\
\text { narrativos con los éticos. }\end{array}$ & $\begin{array}{l}\text { Se realizó un análisis del vjb } \\
\text { This War of Mine, posterior- } \\
\text { mente se entrevistó a sus } \\
\text { creadores para conocer } \\
\text { cómo lo habían diseñado y } \\
\text { las elecciones morales que } \\
\text { incluyeron. }\end{array}$ & $\begin{array}{l}\text { El vj plasma la memoria de } \\
\text { los conflictos armados en la } \\
\text { Europa del este y el impacto } \\
\text { emocional de las víctimas. } \\
\text { Suscita la reflexión ante los } \\
\text { dilemas morales vividos. }\end{array}$ \\
\hline $\begin{array}{l}\text { Díaz (2014) } \\
\text { Cualitativo: } \\
\text { Estudio de caso } \\
\text { único. }\end{array}$ & $\begin{array}{l}\text { Analizar los elementos de } \\
\text { gamificación del juego } \\
\text { Contra Viento y Marea y para } \\
\text { sensibilizar a los alumnos. }\end{array}$ & $\begin{array}{l}\text { Se analiza la influencia del } \\
\text { juego en el usuario a partir } \\
\text { de las propuestas gamifi- } \\
\text { cadas y los aprendizajes } \\
\text { derivados de los dilemas } \\
\text { morales planteados. }\end{array}$ & $\begin{array}{l}\text { La gamificación de escena- } \\
\text { rios bélicos y el juego en } 1^{\text {a }} \\
\text { persona ayuda a compren- } \\
\text { der y empatizar con las vícti- } \\
\text { mas al decidir en situaciones } \\
\text { límite. Se suscita la reflexión } \\
\text { y el cambio de actitud. }\end{array}$ \\
\hline $\begin{array}{l}\text { Hanes y Stone } \\
\text { (2019). } \\
\text { Cualitativo: Dise- } \\
\text { ño teórico. }\end{array}$ & $\begin{array}{l}\text { Elaborar un modelo ga- } \\
\text { mificado para presentar la } \\
\text { información histórica en un } \\
\text { serious game. }\end{array}$ & $\begin{array}{l}\text { Se diseña un modelo gamifi- } \\
\text { cado para incluir contenidos } \\
\text { históricos en serious games } \\
\text { apoyado en el Aprendizaje } \\
\text { basado en videojuegos. } \\
\end{array}$ & $\begin{array}{l}\text { El modelo gamificado es útil } \\
\text { para aprender y explorar el } \\
\text { contenido patrimonial en un } \\
\text { juego histórico. }\end{array}$ \\
\hline $\begin{array}{l}\text { Maniega, Yánez } \\
\text { y Lara (2011) } \\
\text { Cualitativo: Dise- } \\
\text { ño teórico. }\end{array}$ & $\begin{array}{l}\text { Crear un Ambiente Virtual de } \\
\text { Aprendizaje Inmersivo (AVAI), } \\
\text { apoyado en una metodolo- } \\
\text { gía, tecnología y contenidos } \\
\text { innovadores. }\end{array}$ & $\begin{array}{l}\text { Se definen los rasgos de } \\
\text { un Ambiente Virtual de } \\
\text { Aprendizaje Inmersivo (AVAI) } \\
\text { para la crear un prototipo de } \\
\text { serious game que facilite la } \\
\text { inmersión en el aprendizaje. }\end{array}$ & $\begin{array}{l}\text { La inmersión en un mundo } \\
\text { virtual motivador ayuda a } \\
\text { experimentar y aprender. } \\
\text { Se favorece la interacción } \\
\text { y el entrenamiento de } \\
\text { habilidades al simular una } \\
\text { realidad casi tangible. }\end{array}$ \\
\hline
\end{tabular}




\section{DISGUSIÓN}

Aunque no se han encontrado revisiones anteriores identificando los distintos ámbitos desde los que se abordan los videojuegos bélicos, si existen estudios puntuales ligados a experiencias concretas con un determinado videojuego. Además, se concentran en cuatro áreas de conocimiento y responden a motivaciones muy distintas. Predominan las investigaciones ligadas al contexto educativo cerca de la mitad $(43,25 \%)$ (Tabla 2 y 3$)$, se observa que la mayoría opta por metodologías cualitativas, estudios de casos y, algún estudio adopta por una metodología mixta de tipo descriptivo. Los instrumentos empleados fueron cuestionarios creados ad hoc, entrevistas y tests para recabar datos de los sujetos. Entre los resultados que destacan los autores, cabe señalar que algunos videojuegos bélicos incorporados en el aula favorecen la comprensión de la historia, la motivación del alumnado, la interacción social y la reflexión a partir de las estrategias del juego. Algunos generan experiencias envolventes para aprender historia, disipan mitos sobre la IGM y IIGM, promueven la investigación crítica, el análisis comparativo y estimulan el espíritu crítico (Chapman, 2016).

Puntualmente, O'Neil y Feenstra (2016) señalan que Medal of Honor: Frontline ofrece datos fiables para conocer hechos históricos y potenciar la empatía, y el serious game Making History incrementa la motivación y el compromiso del alumnado para aprender historia. Igualmente, el uso del serious games Peacemaker -que aboga por la paz- contribuye a cambiar de actitud frente a la guerra o a colectivos estigmatizados, y puede activar la empatía histórica.

Sin embargo, Gish (2010) y Payne (2014) consideran que Call of Duty ofrece una visión reduccionista de la guerra, subraya la violencia, no propicia el pensamiento crítico, y pese a aportar datos históricos, omite las causas y repercusiones de la guerra. Otros autores demuestran que estos juegos bélicos no sólo no activan habilidades cognitivas importantes, sino que incluso afianzan estereotipos de género $y$ raza (Burguess et al., 2011). Finalmente, algunos investigadores abogan por implicar a expertos historiadores en el diseño de videojuegos bélicos para dotarlos de mayor fiabilidad para conocer e interpretar el pasado, limitando el sesgo reduccionista de la historia y la guerra, y propugnan la creación de un modelo didáctico que rescate el potencial de los videojuegos (Metzger \& Paxton, 2016).

Por su parte, los estudios analizados del ámbito de la psicología representan $(10,20 \%)$ (Tabla 4 y 5 ) y priman una metodología de carácter cuantitativo y mixto. Diseñan y validan instrumentos, por un lado, para medir la capacidad inmersiva de los videojuegos y su relación con la adquisición de conocimientos (Cheng, She \& Annetta, 2014). Y por otro, crean instrumentos para identificar los componentes afectivos, cognitivos y conductuales generados por los juegos que se relacionan con la adhesión de los jugadores (Zaib, Hool \& Hlavacs, 2016). Asimismo, otros estudios analizan los efectos de determinados videojuegos en los sujetos, alertando del desarrollo de comportamientos problemáticos debido a la adicción que generan (Maga- 
nuco et al., 2019). Y otros concluyen que la exposición a videojuegos violentos puede favorecer la tolerancia hacia comportamientos no éticos en jóvenes (Teng et al., 2019).

Las investigaciones del ámbito sociológico y/o antropológico representan un $27 \%$ (Tabla 6), abarcan un amplio espectro metodológico: estudios cualitativos centrados en estudio de caso o casos únicos apoyados en análisis de contenido, mediante parrillas de observación; métodos mixtos de tipo descriptivo que utilizan cuestionarios para recabar opiniones de sujetos. Algunos autores concluyen que los videojuegos bélicos presentan una implicación, conexión emocional y empatía de los jugadores con las víctimas menor que el cine. También señalan que algunos videojuegos fomentan la militarización, apelan a la defensa propia para legitimar los conflictos bélicos internacionales, caricaturizan o desdramatizan la guerra, mostrando a los protagonistas como héroes invulnerables, y limitan la visión crítica de los jugadores (Robinson \& Schulzke, 2016). Advierten que estos instrumentos pueden convertirse en plataformas de propaganda ideológica y/o nacionalista y pueden fomentar el reclutamiento militar.

Los estudios de casos focalizados al análisis de juegos específicos concluyen que: Spec Ops: The Line favorece la reflexión y provoca un sentimiento de culpa en el jugador por las decisiones tomadas; This war of Mine muestra el impacto emocional de la guerra en las víctimas, permitiendo reflexionar sobre dilemas morales, y la saga Metal Gear ofrece una mirada crítica de la Guerra Fría de los bandos enfrentados. Mientras, el estudio centrado en la saga Call of Duty muestra la visión sesgada de distintos conflictos bélicos al omitir la presencia y el sufrimiento de civiles (Verino, 2019). Por último, algunos autores defienden la necesidad de integrar mecánicas en los videojuegos que promuevan y gratifiquen a los jugadores que adopten estrategias no bélicas.

Los estudios sobre el diseño técnico de videojuegos o serious games, limítrofes al campo tecnológico son minoritarios representan un 13,50\% del total analizados (Tabla 7), poseen una metodología cualitativa centrada en el estudio de casos identificando distintas dimensiones de análisis. Los autores subrayan la importancia de dotar de jugabilidad al diseño de videojuegos que transmitan contenidos educativos, para garantizar la permanencia de los jugadores y el aprendizaje en escenarios atractivos mediante la superación de niveles. También apuestan por modelos gamificados que ayuden a explorar y comprender contenidos históricos de los conflictos bélicos de forma lúdica, provocando la inmersión de los jugadores en mundos virtuales que fomenten el aprendizaje (Maniega, Yánez \& Lara, 2011).

\section{GONCLUSIONES}

Hay que resaltar que no existen revisiones de investigaciones anteriores sobre videojuegos bélicos que confronten las metodologías adoptadas en función del área de conocimiento desde donde se realizan. Con este estudio se han podido identificar y analizar los distintos ámbitos de abordaje de las oportunidades educativas y limi- 
taciones que ofrecen estos artefactos lúdicos y las motivaciones de los investigadores dependiendo de su área de procedencia. Para algunos, estos videojuegos contribuyen a motivar el aprendizaje de contenidos de carácter histórico, aunque reconocen que no todos recogen con fidelidad los datos históricos, algunos se limitan a presentar acontecimientos de forma trivial y descontextualizada, omitiendo elementos tan importantes como las causas que motivaron las guerras y las consecuencias que se derivaron de ellas. Además, invisibilizan a las víctimas y sus secuelas, presentando personajes totalmente deshumanizados cuya única labor es avanzar a través de las fuerzas enemigas para derrotarlas, sin permitir la reflexión de los jugadores sobre sus actos.

Se contempla un panorama polarizado, por un lado hay un sector que no considera a estos videojuegos aptos para utilizarse desde una perspectiva educativa, por tildarlos de plataformas de propaganda militarista o nacionalista que sirve a intereses ideológicos. Y por otro, están los investigadores-docentes quienes han puesto mayor énfasis en la utilización de estos videojuegos como recurso histórico, concretamente ligados a la I y II GM, que permiten al alumnado participar en acontecimientos pasados virtualmente, aprendiendo de una forma lúdica e inmersiva. Sin embargo, se echa en falta estudios que profundicen en el aspecto crítico que pueden otorgar estos videojuegos, facilitando el pensamiento crítico y la reflexión gracias a la forma tan directa y descarnada que tienen de mostrar los acontecimientos. De ahí, que las líneas futuras de investigación -de quienes han realizado este estudio- se dirijan a analizar su potencialidad para activar el pensamiento crítico.

Tras constatar la parcelación de los estudios analizados ubicados en áreas de conocimiento con intereses dispares, se precisarían investigaciones que involucraran a equipos interdisciplinares para enriquecer los resultados. Lo que revertiría en el enriquecimiento mutuo, al propiciar diseño de videojuegos educativos o serious games que aborden conflictos bélicos, desde el rigor histórico, que potencien su atractivo y su componente lúdico. Al tiempo que susciten la reflexión y el pensamiento crítico sobre la guerra, para poder implementarse en los contextos educativos.

\section{REFERENGIAS BIBLIOGRÁFICAS}

Alhabash, S., \& Wise, K. (2015). Playing their game: changing stereotypes of Palesti: nians and Israelis through videogame play. New Media \& Society, 17(8), 1358-1376. https://doi.org/10.1177/1461444814525010

Bean, A.M., Nielsen, R.K., Van Rooij, A.J., \& Ferguson, C.J. (2017). Video game addiction: The push to pathologize video games. Professional Psychology: Research and Practice, 48(5), 378-389. https://doi.org/10.1037/pro0000150.

Boltz, L.O. (2017). "Like Hearing From Them in the Past": The Cognitive-Affective Model of Historical Empathy in Video Game Play. International Journal of Gaming and Computer-Mediated Simulations (IJGCMS), 9(4), 1-18. DOI: 10.4018/IJGCMS.2017100101 
Burgess, M.C.; Dill, K.E.; Stermer, S.P.; Burgess, S.R.; \& Brown, B.P. (2011). Playing with prejudice: The prevalence and consequences of racial stereotypes in video games. Media Psychology, 14(3), 289-311. DOI: 10.1080/15213269.2011.596467 https://bit. ly/37jlvT2

Camarero, J. (2019). Propuesta didáctica de Historia y videojuegos a partir del videojuego Total War: Rome II (Trabajo Fin de Máster). Universidad Pública de Navarra. https://bit.ly/2vu7m8I

Carvajal Gutiérrez,G.; Rojas Zambrano, P.A. y Murcia Londoño, E. (2016). El videojuego "El misterio de la pirámide", una propuesta interactiva para el aprendizaje de las matemáticas. Anduli, 15, 177-188. http://dx.doi.org/10.12795/anduli.2016.i15.10

Carvalho, V.M. (2017). Videogames as Tools for Social Science History. The Historian, 79(4), 794-819. https://doi.org/10.1111/hisn.12674

Carvalho, B., Soares, M., Neves, A., Soares, G., \& Lins, A. (2016). Virtual reality devices applied to digital games. A literature review. In M. Soares \& F. Rebelo (ed.) Ergonomics in Design: Methods and Techniques, (pp. 125-136). Florida, USA: CRC Press.

Chapman, A. (2016). It's hard to play in the trenches: World War I, collective memory and videogames. Game Studies, 16(2). https://bit.ly/3a0OUUk

Cheng, M.T., She, H.C., \& Annetta, L.A. (2015). Game immersion experience: its hierarchical structure and impact on game-based science learning. Journal of Computer Assisted Learning, 31(3), 232-253. https://doi.org/10.1111/jcal.12066

Christy, K.R., \& Fox, J. (2016). Transportability and presence as predictors of avatar identification within narrative video games. Cyberpsychology, Behavior, and Social Networking, 19(4), 283-287. https://doi.org/10.1089/cyber.2015.0474

Clearwater, D.A. (2010). Living in a militarized culture: war, games and the experience of US empire. TOPIA: Canadian Journal of Cultural Studies, 23, 260-285. https://doi. org/10.3138/topia.23-24.260

Cuenca, J.M., \& Martín, M.J. (2010). Virtual games in social science education. Computers \& Education, 55(3), 1336-1345. https://doi.org/10.1016/j.compedu.2010.05.028

De Lope, R.P., Medina, N., Montes, R., Mora, A. \& Gutiérrez, F.L. (2017, September). Designing educational games: Key elements and methodological approach. In 9th International Conference on Virtual Worlds and Games for Serious Applications (VSGames), (pp. 63-70). New York: IEEE. DOI:10.1109/VS-GAMES.2017.8055812

De Smale, S., Kors, M.J., \& Sandovar, A.M. (2019). The case of This War of Mine: A production studies perspective on moral game design. Games and Culture, 14(4), 387409. https://doi.org/10.1177/1555412017725996

Del Moral, M.E., \& Guzmán, A.P. (2017). Perfil de jugador virtual asociado a la motifi vación personal para jugar en CityVille. Revista de Educación a Distancia, 54, 1-20. DOI: http://dx.doi.org/10.6018/red/54/3 
Revisión sistemática de investigaciones...- M.E. del Moral y C. Rodríguez

Díaz, J. (2014). El uso de la Gamificación en el tercer sector: el caso del videojuego "Contra viento y marea" de ACNUR. En M.J. Cartes-Barroso (coord.) Derechos humanos emergentes y periodismo, (pp. 315-323). Sevilla: Universidad de Sevilla.

Donald, I. (2019). Just War? War Games, War Crimes, and Game Design. Games and Culture, 14(4), 367-386. https://doi.org/10.1177/1555412017720359

Dyer-Witheford, N., \& De Peuter, G. (2009). Games of Empire: Global Capitalism and Video Games. Minneapolis: University of Minnesota Press.

Fisher, S. (2011). Playing with World War II: A small-scale study of Learning in Video Games. Loading..., 5(8), 71-89. https://bit.ly/3aJxzil

Forde, M. (2020). Tencent's TiMi Studios discuss Call of Duty: Mobile, Pokémon partnership, and 2020 trends. Pocket Gamer. https://bit.ly/3cOLFki

Frasca, G. (2009). Juego, videojuego y creación de sentido. Una introducción. Revista Internacional de Comunicación Audiovisual, Publicidad y Literatura, 1(7), 37-44. https://bit.ly/2VsJbRe

García-González, V. (2016). Explicar las guerras: didáctica de la guerra en las ciencias sociales. Opción: Revista de Ciencias Humanas y Sociales, 11, 567-587.

García-Moreno, R. (2017). La Historia a través de los videojuegos: La Guerra Fría en la saga Metal Gear (Trabajo Fin de Máster). Universidad de Valladolid. https://bit. ly/2W0jaKU

González, A., \& Igartua, J.J. (2020). Dehumanization and Legitimization of Armed Conz flicts in War Video Games. Palabra Clave, 23(1), e2314. http://dx.doi.org/10.5294/ pacla.2019.23.1.4

Gish, H. (2010). Playing the Second World War: Call of Duty and the telling of history. Eludamos. Journal for Computer Game Culture, 4(2), 167-180.

Hanes, L., \& Stone, R. (2019). A model of heritage content to support the design and analysis of video games for history education. Journal of Computers in Education, 6(4), 587-612. https://doi.org/10.1007/s40692-018-0120-2

Holdijk, E. (2016). Playing the Great War: Getting Historians Involved in Video Games (Doctoral dissertation). The University of Victoria, Canada. https://bit.ly/2tP1YMA

Maganuco, N.R., Costanzo, A., Midolo, L.R., Santoro, G., \& Schimmenti, A. (2019). Impulsivity and alexithymia in virtual worlds: a study on players of World of WarCraft. Clinical Neuropsychiatry, 16(3), 127-134. https://bit.ly/2U0wei0

Maniega, D., Yanez, P., \& Lara, P. (2011). Uso de un videojuego inmersivo 3D para el aprendizaje del español: El caso de" Lost in La Mancha”. Revista ICONO14, 9(2), 101-121. https://doi.org/10.7195/ri14.v9i2.50

Marcano, B.E. (2014). Factores emocionales en el diseño y la ejecución de videojuegos y su valor formativo en la sociedad digital: El caso de los videojuegos bélicos (Vol. 344). (Tesis Doctoral). Salamanca: Ediciones Universidad de Salamanca. https://bit.ly/ 2YaXTiL 
Metzger, S.A., \& Paxton, R.J. (2016). Gaming history: A framework for what video games teach about the past. Theory \& Research in Social Education, 44(4), 532-564. DOI: 10.1080/00933104.2016.1208596

Moher, D., Shamseer, L., Clarke, M., Ghersi, D., Liberati, A., Petticrew, M., Shekelle, P., Stewart, L.A. \& PRISMA-P Group (2015). Preferred reporting items for systematic review and meta-analysis protocols (PRISMA-P) 2015 statement. Systematic Reviews, 4(1). https://doi.org/10.1186/2046-4053-4-1

Nardone, R. (2017). Videogames between ethics and politics. Ricerche di Pedagogia e Didattica. Journal of Theories and Research in Education, 12(2), 41-55. https://rpd.unibo.it/article/view/7072/6799

Navarro, J. (2017). El videojugador. Barcelona: Anagrama.

O’Neill, K. \& Feenstra, B. (2016). 'Honestly, I Would Stick with the Books': Young Adults' Ideas about a Videogame as a Source of Historical Knowledge. Game Studies, 16(2). http://gamestudies.org/1602/articles/oneilfeenstra

Örtqvist, D., \& Liljedahl, M. (2010). Immersion and gameplay experience: A contingency framework. International Journal of Computer Games Technology, 1-12. https://doi. org/10.1155/2010/613931

Payne, M.T. (2014). War bytes: the critique of militainment in Spec Ops: The Line. Critical Studies in Media Communication, 31(4), 265-282. https://doi.org/10.1080/1529 5036.2014.881518

Pötzsch, H. (2017). Selective realism: Filtering experiences of war and violence in first-and third-person shooters. Games and culture, 12(2), 156-178. https://doi. org/10.1177/1555412015587802

Robinson, N. (2012). Video games, Persuasion and the War on Terror: Escaping or Embedding the Military-Entertainment Complex?. Political Studies, 60(3), 504522. https://doi.org/10.1111/j.1467-9248.2011.00923.x

Robinson, N., \& Schulzke, M. (2016). Visualizing War? Towards a Visual Analysis of Videogames and Social Media. Perspectives on Politics, 14(4), 995-1010. https://bit. ly/2ON2Ubv

Rookwood, J., \& Palmer, C. (2011). Invasion games in war-torn nations: can football help to build peace?. Soccer \& Society, 12(2), 184-200. https://doi.org/10.1080/14660970 .2011 .548356

Saber, D., \& Webber, N. (2017). 'This is our Call of Duty': hegemony, history and resistant videogames in the Middle East. Media, Culture \& Society, 39(1), 77-93. https://doi. org/10.1177/0163443716672297

Shaw, I.G.R. (2010). Playing war. Social \& Cultural Geography, 11(8), 789-803. https:// doi.org/10.1080/14649365.2010.521855

Sherry, J.L., Lucas, K., Greenberg, B.S., \& Lachlan, K. (2006). Video game uses and gratifications as predictors of use and game preference. Playing video games: Motives, responses, and consequences, 24(1), 213-224. https://bit.ly/3e5gPnM 
Revisión sistemática de investigaciones...- M.E. del Moral y C. Rodríguez

Šisler, V. (2016). Contested Memories of War in Czechoslovakia 89-38: Assassination: Designing a Serious Game on Contemporary History. Game Studies, 16(2). https:// bit.ly/2W $4 \mathrm{mlj} 6$

Teng, Z., Nie, Q., Guo, C., Zhang, Q., Liu, Y., \& Bushman, B. J. (2019). A longitudinal study of link between exposure to violent video games and aggression in Chinese adolescents: The mediating role of moral disengagement. Developmental Psychology, 55(1), 184-195. https://doi.org/10.1037/dev0000624

Unsworth, N.; Redick, T.S.; McMillan, B.D.; Hambrick, D.Z., Kane, M.J. \& Engle, R.W. (2015). Is playing video games related to cognitive abilities?. Psychological science, 26(6), 759-774. https://doi.org/10.1177/0956797615570367

Verino, C.L. (2019). Aspectos hollywoodenses de la imagen de Segunda Guerra Mundial recreada en Call Of Duty. E-tramas, 4, 46-57. https://bit.ly/2Qlbdwb

Walk, W., Görlich, D., \& Barrett, M. (2017). Design, dynamics, experience (DDE): an advancement of the MDA framework for game design. In O. Korn \& N. Lee (ed.), Game Dynamics, (pp. 27-45). Cham: Springer. https://doi.org/10.1007/978-3-31953088-8_3

Watson, W.R.; Mong, C.J.; \& Harris, C.A. (2011). A case study of the in-class use of a video game for teaching high school history. Computers \& Education, 56(2), 466-474. https://doi.org/10.1016/j.compedu.2010.09.007

Weibel, D., \& Wissmath, B. (2011). Immersion in computer games: The role of spatial presence and flow. International Journal of Computer Games Technology, 2011. https://doi.org/10.1155/2011/282345

West, J., Chu, M., Crooks, L., \& Bradley-Ho, M. (2018). Strategy war games: how business can outperform the competition. Journal of Business Strategy, 39(6), 3-12. https:// doi.org/10.1108/JBS-11-2017-0154

Zaib. A., Hool, D., \& Hlavacs, H. (2017). Engagement in games: Developing an instrument to measure consumer videogame engagement and its validation. International Journal of Computer Games Technology, ID 7363925, 1-11. https://doi. org/10.1155/2017/7363925 